\title{
HBIM FOR THE SURVEYING, ANALYSIS AND RESTORATION OF THE SAINT JOHN THE THEOLOGIAN CATHEDRAL IN NICOSIA (CYPRUS)
}

\author{
C. Santagati ${ }^{\text {a }}$, C.R. Laurini ${ }^{\text {a }}$, G. Sanfilippo ${ }^{\text {a }}$, N. Bakirtzis ${ }^{\text {b }}$, D. Papacharalambous ${ }^{\text {b }}$, S. Hermon $^{\text {b }}$ \\ ${ }^{a}$ Department of Civil Engineering and Architecture, University of Catania, Via Santa Sofia n. 64, cap 95123, Catania, Italy - \\ cettina.santagati@dau.unict.it, gsanfi@dau.unict.it, laurinicarla@gmail.com \\ ${ }^{\mathrm{b}}$ Science and Technology in Archeology Research Center, The Cyprus Institute, Nicosia, Cyprus \\ - s.hermon@cyi.ac.cy, n.bakirtzis@cyi.ac.cy,d.papacharalambous@cyi.ac.cy
}

KEY WORDS: H-BIM, Photogrammetry, Laser Scanning, Digital Cultural Heritage, Byzantine, Decay mapping

\begin{abstract}
:
The present study illustrates the results of an interdisciplinary collaboration between the Mediterranean Laboratory of Survey and Diagnostics for Architecture (RDA) of the Department of Civil Engineering and Architecture (DICAR) of the University of Catania in Italy and the Andreas Pittas Laboratories for Art Characterisation (APAC) of the Science and Technology in Archaeology Research Center (STARC) of the Cyprus Institute in Cyprus. The research focused on the application of an H-BIM approach in the study of a Mediterranean iconic heritage asset, the St. John Cathedral of Nicosia, built in 1662 on the remains of a monastery from the $15^{\text {th }}$ century. The adopted methodology has provided the framework for a dynamic investigation, constantly evolving along several dimensions: historical, geometric spatial, architectural-constructive identification and mapping of degrade, interpretation of degenerative causes and design proposals.
\end{abstract}

\section{INTRODUCTION}

The project in the field of Cultural assets is flexible; the analytical, diagnostic, design, construction and management phases are, in fact, a unitary process "perpetually in progress". Nowadays, current digital information systems can help to manage this flexibility with a rigorous system of data acquisition and systematization. Nevertheless, we are witnessing a fragmentation of both the documentation and knowledge building processes, which can be overcome through a critical and integrated use of current technologies. The intersection of new cognitive paradigms facilitates the recognition of the values of the heritage structure, leading to more coherent design choices. The adoption of methodologies oriented to parametric design and semantic-aware modelling for existing built heritage, in a perspective of controlled management of all the documentation related to the individual building, thus becomes an efficient and effective method for the knowledge, conservation and restoration of architectural cultural heritage (Santana, 2017; Brumana et al,. 2017).

The present study illustrates the results of an interdisciplinary collaboration (Laurini, 2018) between the Mediterranean Laboratory of Survey and Diagnostics for Architecture (RDA) of the Department of Civil Engineering and Architecture (DICAR) of the University of Catania in Italy and the Andreas Pittas Laboratories for Art Characterisation (APAC) of the Science and Technology in Archaeology Research Center (STARC) of the Cyprus Institute in Cyprus. The research focused on the application of an H-BIM approach in the study of a Mediterranean iconic heritage asset, the St. John Cathedral of Nicosia, built in 1662 on the remains of a monastery from the 15 th century. The single nave church has a layout typical of Orthodox churches in Nicosia, with a narthex to the west and the apse, hidden from the inside by the iconostasis, to the east. It also has a bell tower built in 1858. The main hall is surmounted by a barrel vault with ogival sections supported by transverse arches that discharge their weight on the external buttresses. The interior is richly decorated with mainly 18th century wall paintings and portable icons resting on the lavish wood-carved iconostasis spread all around the church's floor. The church has served as the seat of the Archbishop of Cyprus since 1730 .

The adopted methodology has provided the framework for a dynamic investigation, constantly evolving along several dimensions: historical, geometric spatial, architecturalconstructive identification and mapping of decays, interpretation of degenerative causes and design proposals.

Compared to the traditional restoration project workflow, the BIM approach has allowed the creation of an information model in which both the 3D digital survey data (integrated laser scanner and photogrammetry) and the data relating to the cognitive survey (historiographic research, diachronic analysis, classification of the technological system) have been merged to support the diagnostic investigations (decay mapping), the restoration work and the subsequent management of the building (Dal Mas, 2016). Consequently, a database structure was developed within the HBIM, in order to describe the characteristics of the architectural components from a historical perspective. The problems of modelling in the transition from point clouds to factory components were also addressed, such as issues related to technical specifications for LOD (Level of Development), LOI (Level of Information) LOG (Level of Geometry - Surveying, Modelling, Design, Preserving and Monitoring) and LOA (Level of Accuracy), as well as the problems of interoperability between various software. Furthermore, another relevant issue is linked to the mapping of decay in the available BIM platforms. This is still an open research topic (Chiabrando et al., 2017), and we tested a quick approach very useful in presence of plane surfaces (walls, floors) but not useable in presence of curve surfaces such as vaults.

The paper is structured as follows: after a review of up to the date literature (section 2), the adopted methodology will be outlined (section 3); then the methodology will be applied on the chosen case study (section 4), some remarks on the state of conservation will be done in section 5 , then results will be discussed in section 6 , then section 7 will illustrates the conclusion. 


\section{RELATED WORKS}

In recent years there has been an increasing experimentation of the BIM approach in the field of Cultural Heritage in order to assess its adequacy for documentation, restoration and management of historical heritage (Brumana et al, 2017; Bruno et al, 2018; Della Torre et al, 2019). In a first phase the interest of the researchers has been mainly focused on the problems related to the passage from the point clouds to the creation of parametric models of architectural components of the studied buildings; problems that today are addressed towards approaches ranging from procedural modeling (with a high level of geometric abstraction) to the digital clone that preserves all the geometric irregularities of the surfaces (much more suitable in the case of documentation aimed at restoration). Nowadays, if we want to reason on a fully BIM approach in the field of restoration, it becomes of fundamental importance to be able to record directly on the model the information related to the mapping of degradation (physical and structural). If from a theoretical point of view this direction seems to be the correct one, in practice we come up against the rigidity of commercial platforms, created for new buildings, which do not always respond effectively to the needs of the restoration project. In this sense, an experiment that has moved in this direction has been carried out by (Chiabrando et al, 2017) and provides for the use of "adaptive families" that allow you to draw in the 3 dimensions lines or areas to which you can add additional information parameters useful for the project. The limits of this approach are linked to the geometric characteristics (number of points) of these adaptive components that must be defined as apriori. Another interesting approach is the one linked to the Aioli platform (Pamart et al, 2019) a reality-based 3D annotation platform for the collaborative documentation of heritage artefacts that enables a multi-temporal analysis, in order to allow a followup on the state of its conservation and possible degradation. The 3D representation of the object can directly be enriched with semantic annotations or additional resources related to the object (texts, images, videos, sounds). Our research effort goes in this direction, paying attention towards data enrichment for the preservation and the restoration.

\section{METHODOLOGY}

The aim of this work is to experiment the application of BIM approach to the entire process of the cognitive analysis of the monument, for conservation and restoration purposes. In this direction, several needs and requirements from experts with different skills have been taken into account and shaped the methodological framework that can be summarized according the following steps:

Historical research

Geometrical and Architectural survey by means of digital techniques

Semantic decomposition of the building, identification and classification of technological system

Creation of specific architectural components in BIM environment (parametric families) and verification of the Level of Geometric Accuracy in relation to restoration project requirements

Data enrichment in terms of informative contents such as information related to previous restoration interventions, historic phases, etc

Decay mapping within the chosen BIM platform Extraction from the BIM Model of all the representations useful for the analysis of the state of conservation and the setting of the restoration project framework.

\section{THE CASE STUDY OF SAINT JOHN CATHEDRAL}

\subsection{Historic facts}

For more than 400 years now, a single-nave church stands in the south-eastern historic neighborhood of Nicosia's city center. This limestone church is dedicated to Saint John the Theologian and it is representative of the Greek community in Cyprus and has been a witness and a reference point of many historic events and socio-political turbulences.

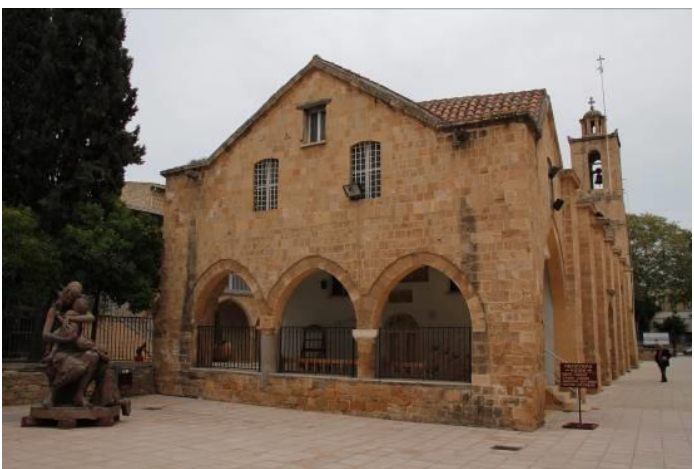

Figure 1. Main façade of Saint John Cathedral in Nicosia

The history of the building goes back to the medieval times. According to some researchers, the church was built on the site where the monastery of Saint John of Bibi used to be

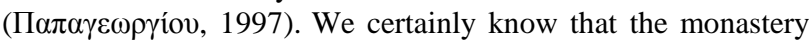

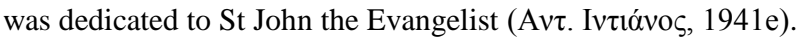
The main façade of the church to the West (fig.1) bares evidence according the dating and the identity of the building. Three stone tablets of an earlier chronological period had been re-used and inserted above this entrance, each one placed on top of the other, when the church was built. The rectangular marble tablet in the middle is decorated in bas relief bares an inscription which informs us that this church was built from its base from the hands of the Archbishop of Cyprus Nicephorus on Wednesday, April $30^{\text {th }}$ in 1662. Archbishop Nicephorus was still in office according to the inscription. Therefore, the church had probably been completed between 1662 and 1674 (Papageorgiou, 2014).

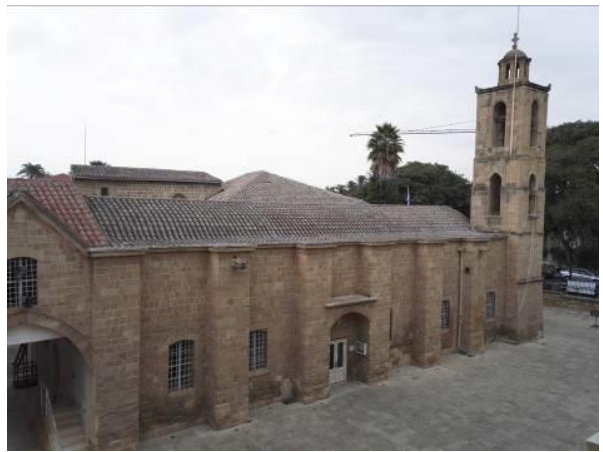

Figure 2. Northen façade with the bell tower

A century later, around 1779, an extension of the women's gallery had as a result the demolition of the upper level of the nave's western wall and the rebuilt of it further to the west (Papageorgiou, 2014). This extension possibly happened since the monastery stopped functioning and the church was transformed to the cathedral of the Orthodox Church of the island. The church became parish and a women's gallery was indispensable. In 1858, when the Orthodox churches got the 
permission from the Ottomans to have bells, the cathedral of Nicosia also obtained the distinguished bell-tower (fig.2).

The Archbishop Philotheos, who served as an Archbishop of Cyprus between 1734 and 1759 was responsible for the church's decoration. Also, the prelates in the semicircular barrel-vault of the apse were painted again by Philotheos in 1736. The lower two zones of the eastern end of the north and south wall seem to have accepted a later repainting considering the different style.

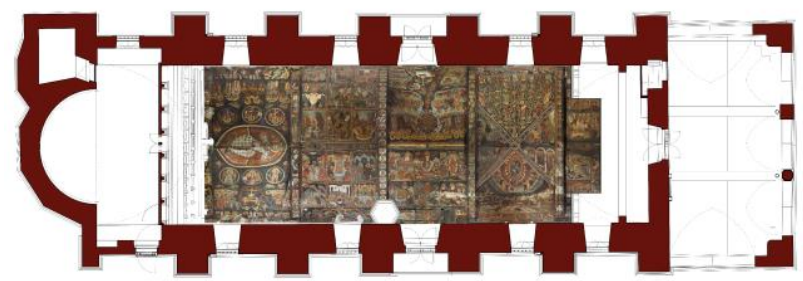

Figure 3. Iposcopic plan with the nave frescoes orthoimage

\subsection{Description of the church}

The St. John cathedral, from the outside, is quite austere, simple and linear. Rectangular in shape, it has two apses semi-circular inside and poligonal outside, and a single nave covered by an ogival ribbed barrel vault (fig. 3).

A narthex anticipates the entrance to the nave, with three ogival arches supported by two marble columns of Roman period. On the first level of the narthex, there is the typical orthodox women's gallery surmounted by a cross vault. At the east there is the bell tower of 1859 that incorporates the smaller apse. All openings have an lintel of low arches. Inside, the bare simplicity of the exterior is contrasted by the splendor of the interior with walls entirely covered with frescoes, crystal candlesticks, wood carvings finished with gold, silver censer and finally the iconostasis in gilded wood dated 1744 (fig.4).
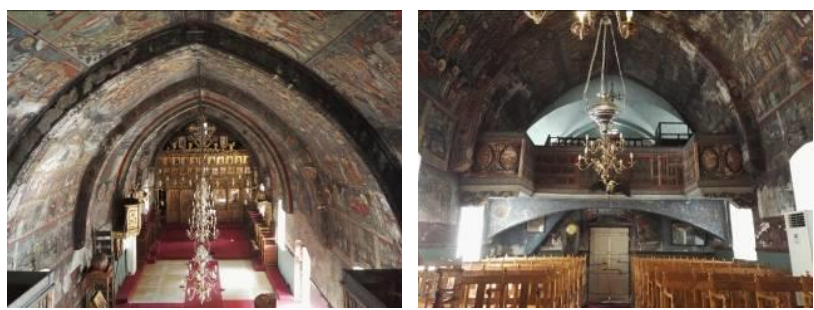

Figure 4. Main nave views towards the iconostasis (left) and the women's gallery (right)

\subsection{Digital Survey}

Architectural surveying has been carried out by using the integration of direct, photogrammetric and laser scanning techniques. After a few cognitive inspections, it was set the acquisition project (fig.5) with the goal of covering and matching properly all the area. Scan positions were established according to the chosen instrument, TLS Surphased 25 HSX (fig. 6). This scheduling was essential for the following data acquisition.

For the scanning of the exteriors there were taken 31 range scans; then one scan was performed for the overlapping between the interior and the exterior; then 41 scans covered the interior rooms (full of sacred furnishings). The overall point cloud has a medium resolution of 7-10 $\mathrm{mm}$, an alignment error of $2 \mathrm{~mm}$ and is constituted by 73 range scans for a total of over
2 billion of points (2.082.339.758). Then, raw data have been processed and elaborated to achieve a more manageable Point Cloud in commercial BIM platforms (such as Revit).

JRC Reconstructor software has been chosen. An automatic Pre-processing has been performed by setting few fundamental parameters (compute normal, noise removal, edge detection, compute confidence).

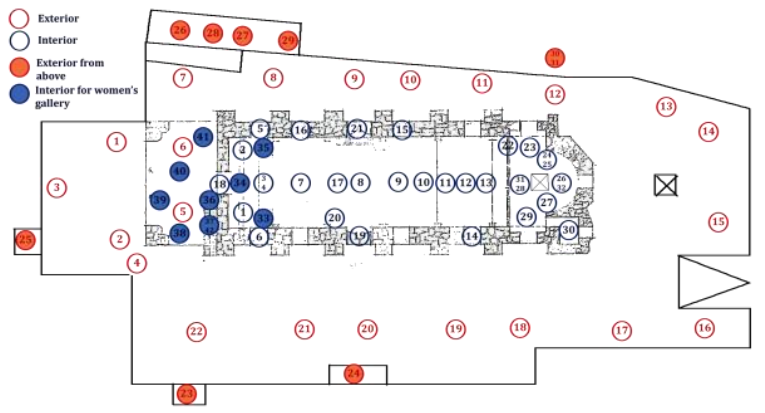

Figure 5. Acquisition project

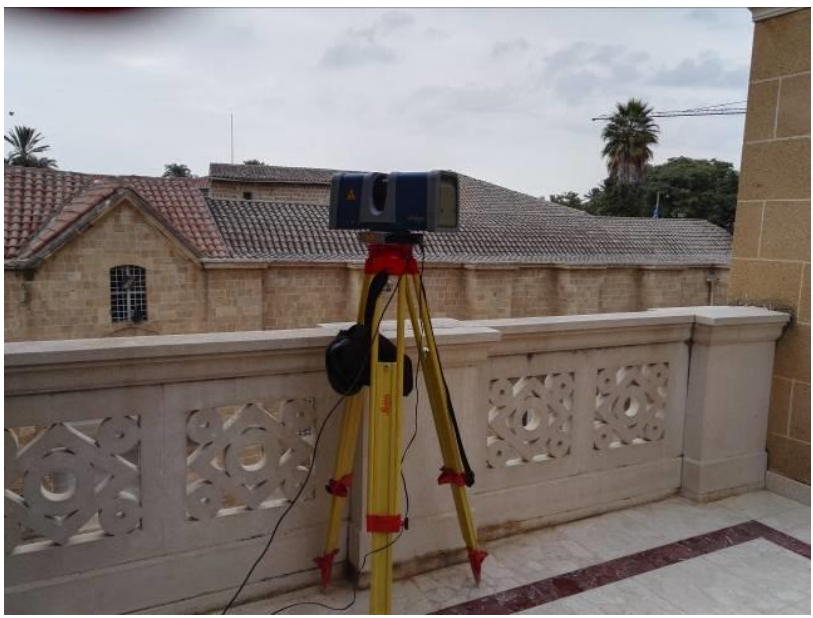

Figure 6. In situ acquisition
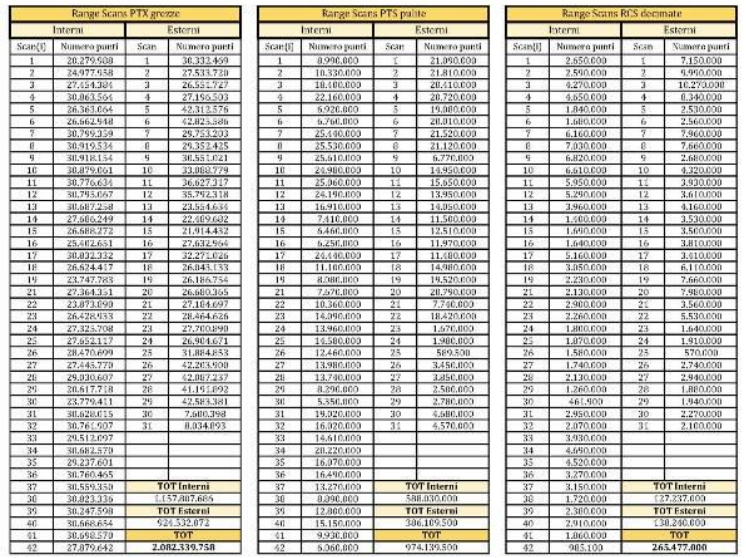

Figure 7. Results of points cleaning and decimation

Then a Pre-Alignment process, followed by a Point-base Registration has been carried out. The alignment between two range scans is based on the Iterative Closest Point (ICP) algorithm. On the case study they were done 30 exterior and 44 interior alignments, with a properly choosing of range scans couples for having an optimal overlapping of common points. 
At the end of the alignment, it was done a cleaning of useless point, passing from 2.082.339.758 to 974.139 .500 points (fig.7).

At the same time of laser scanning acquisition, it was taken a photogrammetric survey (fig.8-10), for integrating the RGB texture to the point cloud. For this purpose, it was used Agisoft Photoscan software. It provides different representations such as: Sparse Cloud, Dense Cloud, Mesh, Textured Mesh, Orthophotos (fig. 11-12).

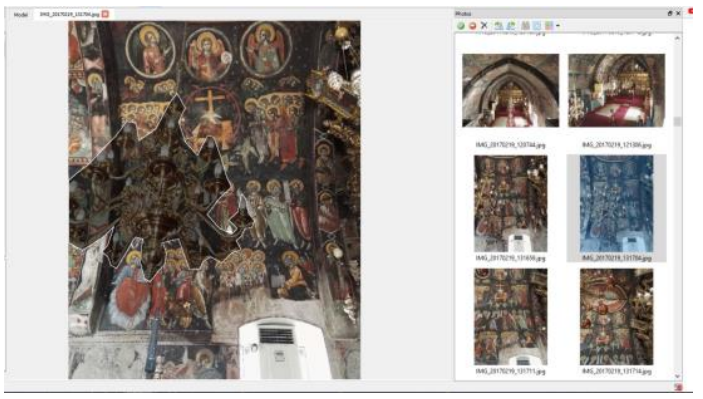

Figure 8. Photomasking step

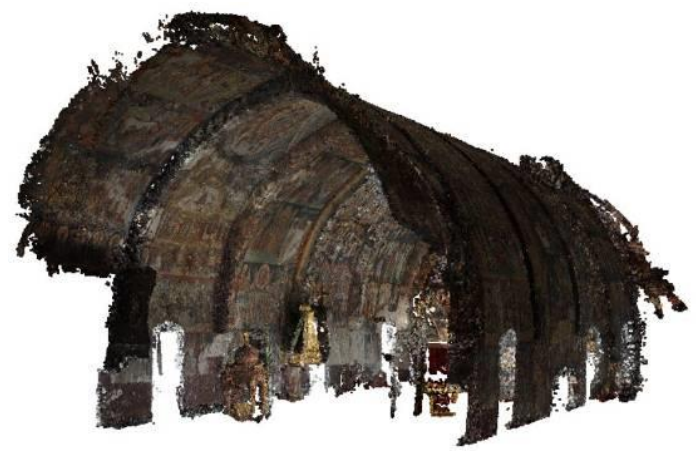

Figure 9. Dense cloud reconstruction of the barrel vault

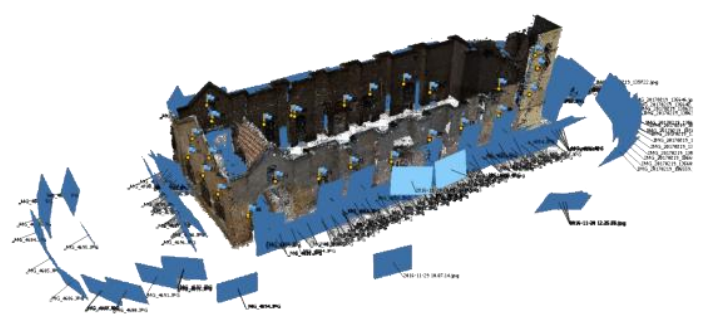

Figure 10. Dense cloud reconstruction of the exterior

\begin{tabular}{|c|c|c|c|c|c|c|}
\hline Name & $\begin{array}{c}N^{*} \text { images } \\
\text { dataset }\end{array}$ & Camera model & $\begin{array}{c}\text { Pixel } \\
\text { resolution }\end{array}$ & $\begin{array}{c}\text { Focal } \\
\text { length }\end{array}$ & $\mathcal{N}^{*}$ points & $\mathcal{N}^{*}$ triangles \\
\hline Vault & 280 & Canon EOS $1100 \mathrm{D}$ & $4272 \times 2408$ & $18 \mathrm{~mm}$ & 1.7073 .161 & 3.910 .511 \\
\hline Apse & 34 & Canon EOS $1100 \mathrm{D}$ & $4272 \times 2408$ & $18 \mathrm{~mm}$ & 15.413 .459 & 3.812 .833 \\
\hline South & 67 & Canon EOS $1100 \mathrm{D}$ & $4272 \times 2408$ & $18 \mathrm{~mm}$ & 32.467 .557 & 2.129 .847 \\
\hline North & 45 & Canon EOS $1100 \mathrm{D}$ & $4272 \times 2408$ & $18 \mathrm{~mm}$ & 22.421 .801 & 1.476 .803 \\
\hline West & 28 & Canon EOS $1100 \mathrm{D}$ & $4272 \times 2408$ & $18 \mathrm{~mm}$ & 11.539 .031 & 750.045 \\
\hline East & 29 & Canon EOS $1100 \mathrm{D}$ & $4272 \times 2408$ & $18 \mathrm{~mm}$ & 10.737 .568 & 685.079 \\
\hline
\end{tabular}

Figure 11. Information regarding datasets acquisition
For the optimization of the processing it was necessary to work with two chunks, one for the exterior and the other one for the interior of the church and then realign them.

Finally, for the alignment between the photogrammetric point cloud and the laser scanning point cloud it was used Cloud Compare to extract a list of common coordinates that was imported in Photoscan for the scaling and alignment. This way all the obtained point clouds refer to a unique reference system and can be overlapped in each other software.

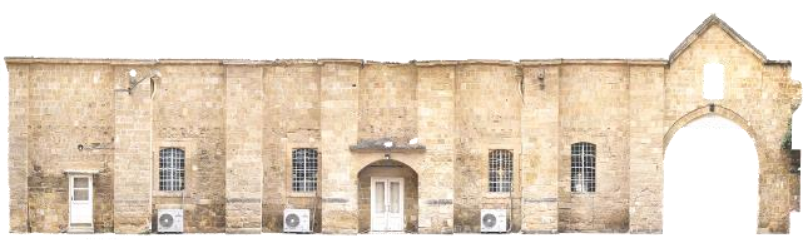

Figure 12. South elevation orthoimage

\subsection{Building techniques identification}

The cognitive investigation involved a preliminary phase for the classification of the technical-constructive system: we identified, with specific codes, materials and architectural components of the church, comparing surveys and historical data (fig. 13).

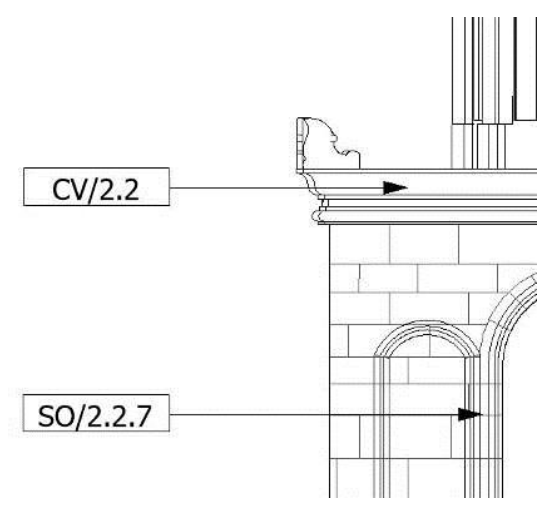

Figure 13. Building techniques identification codes

The historical masonries of Nicosia are usually rubble filled (fig.14): two squared stone vestments filled with a conglomerate of smaller stones, river pebbles and fragments of earthenware, plaster-based mortar and local sands (Christou, Elliotis, 2016).

The Saint John cathedral stands on the remains of ancient foundations of the monastery of Bibi (XV century) and was built with techniques related to the local construction tradition. The wall structures (120 cm thick) have external facing made up of rows of well-squared isodomic ashlars, interspersed with diatons. Most of the ashlars come from buildings of previous eras: the columns of the narthex (from the Roman era) and the coats of arms of the Lusignan-Venetian era. The mortar is made, as usual in Cyprus, from a mixture of clay, sand and straw.

The masonries of the bell tower and the narthex probably consist of a single face in coursed roughly squared ashlars of calcarenite (with maximum size of about $40-45 \mathrm{~cm}$ ).

The floor of the church is most likely made up of a beaded of sand and lime, and grit flooring.

Three different construction solutions have been found for the intermediate floors: a wooden floor (dating back to 1779) warped between the perimetral masonry and a lowered arch, which is the floor of the 'women's gallery'; an elevation in 
reinforced concrete dating back to 1858; a barrel vault (probably made of stone and mortar) placed at the first level of the bell tower.

The intrados of the roof structures is vaulted and with slopes slightly inclined to the extrados. They are all made of local limestone ashlars. A large ogival barrel vault, in square ashlars, defines the nave with 6 arched ribs set on the 12 stone buttresses, which rhythmize, on the outside, the side elevations; also the cross vault of the women's gallery is in squared stone as well as the 'semicatine' on the apse.

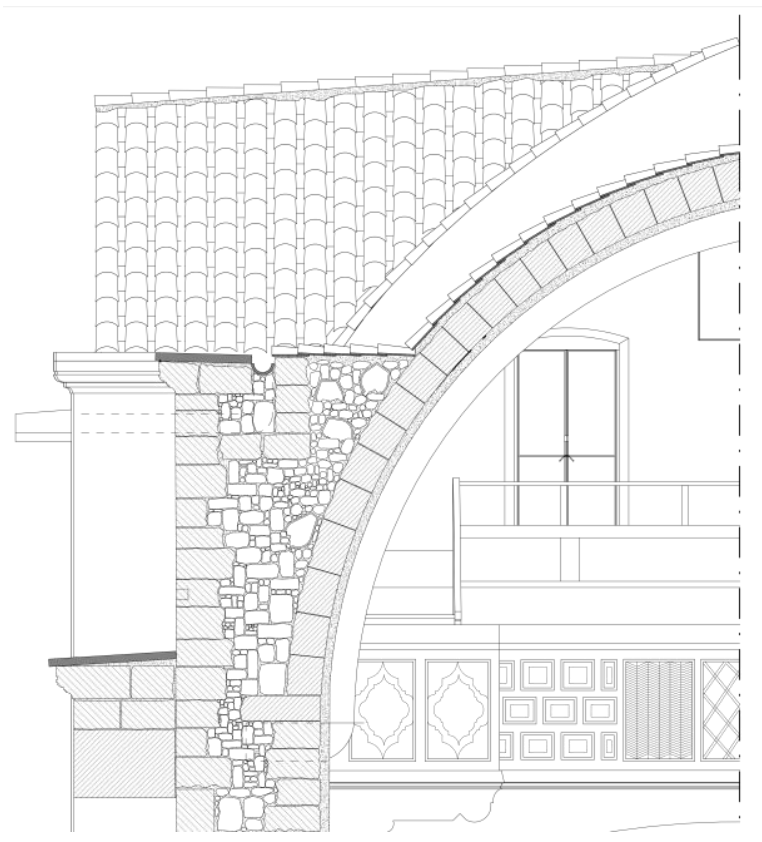

Figure 14. Transversal cross-section with masonry detail

The extrados of all the vaulted structures are covered with a thick layer of beaten mortar (based on lime and gypsum and local inert, probably cement in the cross vault) on which the tiles and canals are placed directly, without a wooden frame. The rainwater is drained through a system of compluves, which convey the water to four limestone gargoyles, now connected to the laminated downspouts. Above the women's gallery, on the other hand, the impluvium (obtained by levelling out the mortar covering above the vault) conveys the water into 4 connections connected to two gargoyles and to the gutter of the nave.

The stone apparatus of the facades is essential and consists of local calcarenite. All the elevations have a crowning that is articulated according to the profile of the buttresses, the slopes and the polygonal apse. The bell tower is marked by stringcourse bands and a frame with small stone leaves in relief at the corners; a lantern with poly-lobed columns and a small dome crowns the tower.

The only original finishings are those that cover the upper part of the nave with the traditional plaster based on lime mortar, plaster and linen on which were spread over time several layers of fresco painting.

\subsection{HBIM modeling}

The point cloud was exported in PTS format to be imported in common BIM-oriented software such as Revit@Autodesk. Before this step the point cloud has been further processed through Recap Pro software @ Autodesk, decreasing the number of points by decimation options and creating a first segmentation using different layers. In order to test a workflow able to facilitate the modeling phase, the plugin Pointsense for Revit has been used.

Indeed, it supports the generation of point cloud portion, exporting region on RFA family, creation of orthophotos $\mathrm{x}$-ray with real dimension, exporting of profile, generation of walls based on point cloud alignment and surface analysis. The use of this plugin was decisive to handle critical issues linked to the passage from the point cloud to the model and the creation of new libraries.

The creation of a BIM model from a point cloud passes through a recognition phase of hierarchical components, the architectural components. As already said, in the case of historical buildings if a researcher or a practitioner would use common BIM-oriented platforms, he must create and divide semantically the manufact as well as to design new libraries of architectural components specifically related to an historical period. The creation of libraries instead of modeling directly in the project environment, allows for a better management (also in terms of size file) and for a reuse of these libraries in other similar projects.

Several architectural elements were identified and classified (walls, vaults, windows) according to common standardized vocabularies and taxonomies.

As regards walls modelling, there were modelled both the two kinds of masonry identified (with different thickness, finish coats, etc) and a first geometrical problem arose in presence of the apse (circular on interior and polygonal on exterior) and the bell tower, because it was not easy to guarantee the right intersection of different geometries.

As regards the vaults, one of the issues was about the possibility to have a geometric modelling against a modelling that would preserve all the irregularities (deformations, depressions) due to the passing of time. For the case study was chosen to follow a geometric modelling for almost all the vaults, using a profile extracted from the point cloud which permitted an enough parametrization (fig. 15), mainly from the informative point of view. Instead, for the cross vault, that presents a strong deformation, it was chosen to model the particular object with real shape, even if at the expense of geometric parameterization.
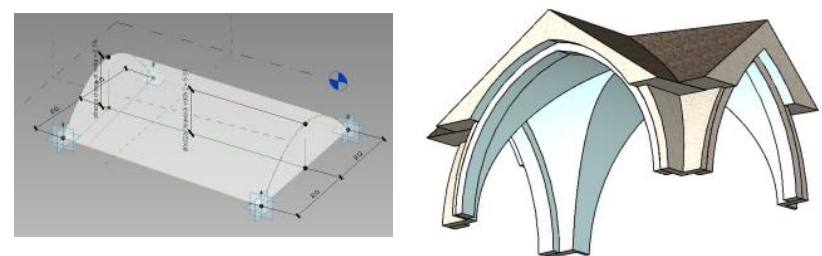

Figure 15. Parametric modelling of a vault (left), generic model of a cross-vault (right)

The other architectural components were modelled using Pointsense plugin and the $\mathrm{x}$-ray orthophotos generated by it (fig. 16).

At the end it was done an analytical comparison between point cloud and $3 \mathrm{~d}$ model carrying out the analysis of points deviation and surfaces. There were analyzed some regions of the model, the most problematic, with a range of $10 \mathrm{~cm}$ maximum. The plug-in generated a colour duplicated surfaces, with in red the positive deviation and in blue the negative deviation. The instrument shows the errors but also the deformation of artefact itself. For example, they were highlighted the not plumb line wall of bell tower, and the vaults deformation (fig. 17). In this way the plug-in resulted useful. 


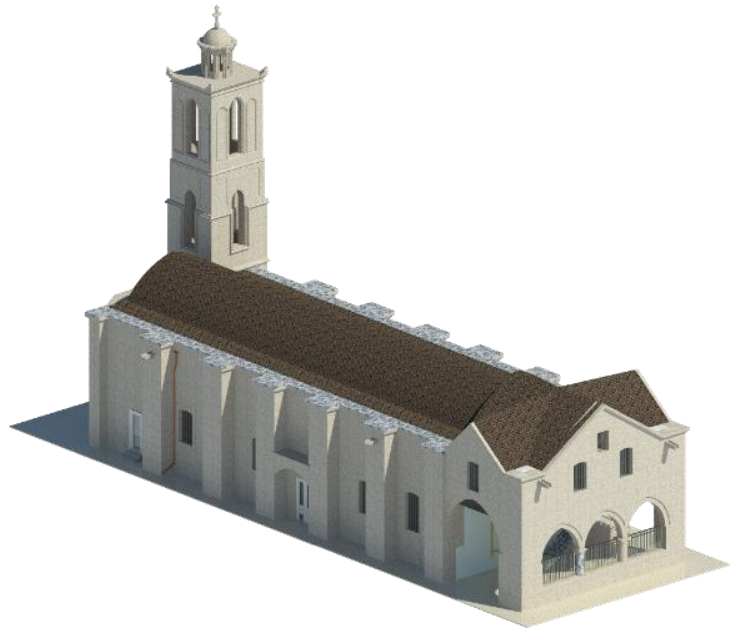

Figure 16. HBIM Model of the Saint John Cathedral
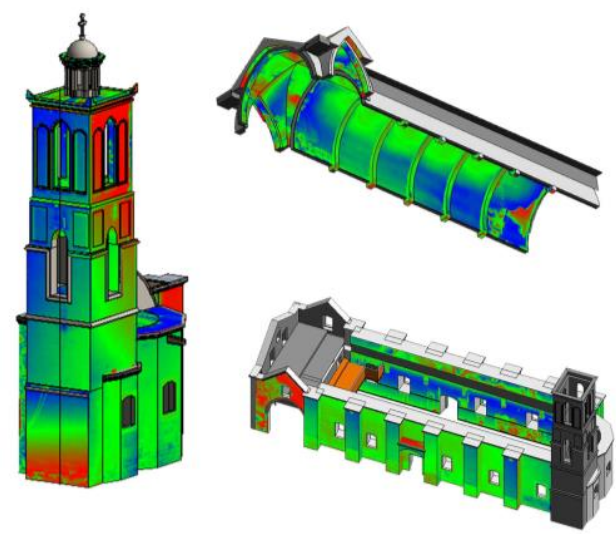

Figure 17. Analytical comparison between point cloud and HBIM Model

\subsection{Data Enrichment}

One of the main features of BIM approach is the possibility to think at the parameterization of the model not only from a geometrical point of view, but also from the informative point of view. Indeed, the data enrichment process is very critical as it allows for having a virtual replica of the cultural asset also in terms of information linked to it. In the BIM community there are several indicators that describe how the model has been developed (LOD) according to the level of information and geometric detail it embeds.

The international standards for AEC field (PASS1192-2:2013) foresee from LOD 100 to LOD 500, considering also the socalled Level of Detail (G1-G2-G3). The recent Italian legislation UNI11337:2017 defines LODs from A to G, considered as the results of the combination of the Level of Geometry (LOG) and Level of Information (LOI).

In the case of an historical building, the as-built condition corresponds to LOD 400 according to international law and LOD F or G according to Italian one (Pavan et al., 2017). Nevertheless, if we consider the required times for diagnostic investigations, it becomes extremely difficult to achieve the same LOD for each architectural component. A good compromise is to assign a shared parameter that describes the different LODs, with the possibility of an updating during the time (fig. 18).

The same approach has been followed for the description of the diachronic analysis (fig. 19): the specification of the construction year/century for each architectural component allows to understand better the different phases of Saint John Cathedral. Working with a commercial software, several technical issues have been faced: the software doesn't permit to assign a different parameter value to the same wall; to bypass this problem we worked inside the panel material and had a different colour for the wall layers showing the different periods creation.

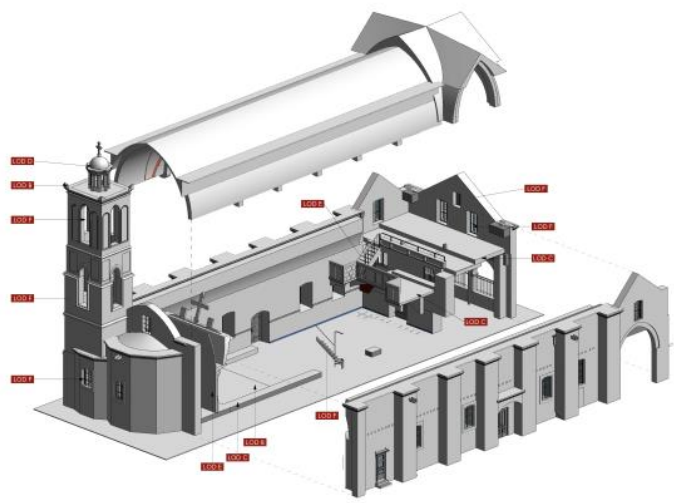

Figure 18. Identification of LODs for each architectural component
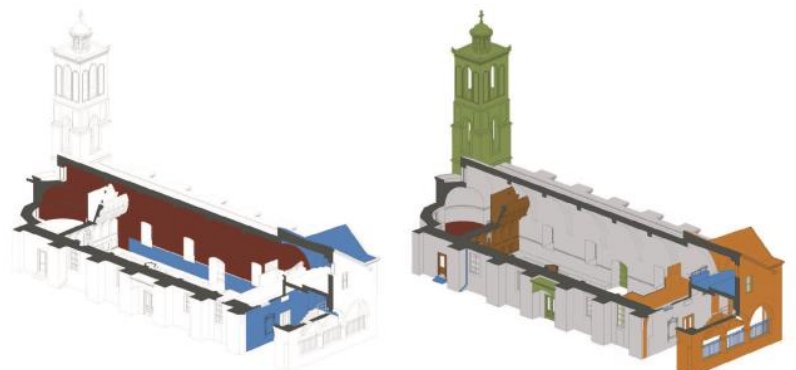

Figure 19. Diachronic analysis with filters and visualization setup

Another critical passage was the classification of technological system in the BIM-oriented software, once identified each component, classified according standardizations of the RDA laboratory, a keynote has been assigned to be used in the project.

\subsection{Decay mapping}

As concerns decay mapping, several approaches have been tested in order to obtain a good compromise between the accuracy of the mapping and the time required to obtain it. One possible way was to use the "filled region" a system family that works very well on $2 \mathrm{D}$ surfaces and is visible only in $2 \mathrm{D}$ views (plan, section and elevation). This family has few parameters to set and it is possible to create different types based on decay classification (fig. 20). However, it's not possible to directly extract quantities from a "filled region" in a schedule, for this reason a script has been written via Dynamo VPL plugin for Revit to convert the area into a scheduled parameter; in this way for each changing of filled 
region the new parameter will be combined with the original one, just restarting dynamo plug-in (fig. 21).

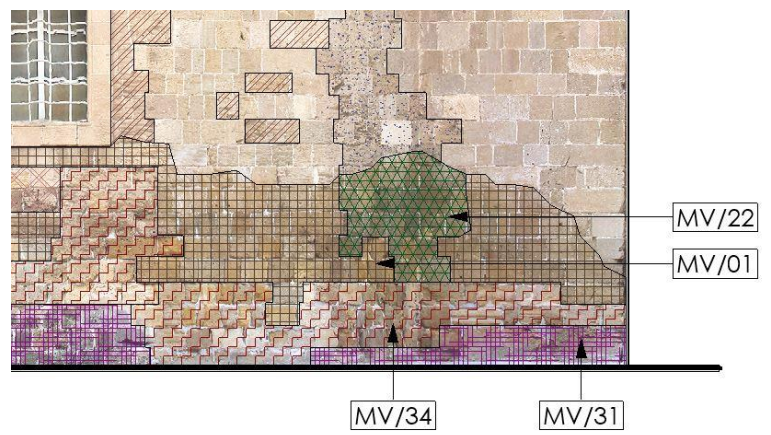

Figure 20. Decays mapping with codes and parametric "filled regions"

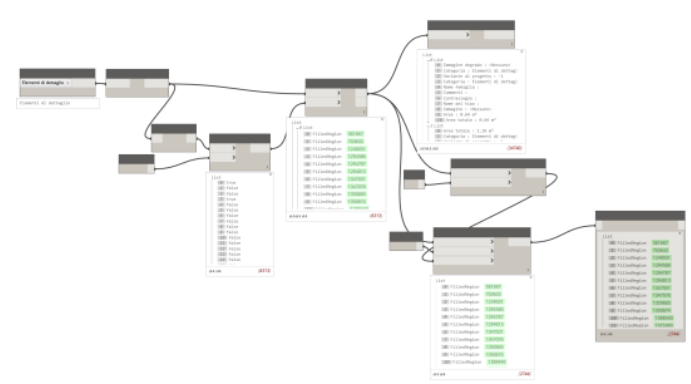

Figure 21. Dynamo script for decay mapping area calculation

This method allows a good parameterization of mapping decay for $2 \mathrm{D}$ surfaces, as regards curved surfaces other examples in literature (adaptive families) to the date remain the best solution, even if there is a problem in the number of points to assign (Lo Turco et al., 2017).

As regards the interventions mapping, the same method has been used working with double codes (the decay and the solving intervention for it).

\section{REMARKS ON THE STATE OF CONSERVATION}

The state of conservation of the Saint John Cathedral is quite good, although cracking survey and analysis, stressed in the decay mapping, have highlighted some critical issues related both to humidity and structural behaviour of the narthex roof. As regards humidity, this problem arose since the construction and was caused by the stone intrinsic physical characteristics (very porous) and by the type of plaster used. The raising of humidity caused the finishings decay: indeed, for this reason the interior was repainted a lot of times. Above all, the lower part was repainted with poorly compatible materials compared to the existing one. Furthermore, the binder and the linen used in the plaster (Solomidou-Ieronymidou, Hasapopoulos, 1993) have contributed to the decay (Solomidou-Ieronymidou, Hasapopoulos, 1993); indeed, this kind of binder favors the absorption of humidity and accelerates the deterioration of the frescoes.

The water has risen by capillarity until a height of about 1.5-2 m. This phenomenon caused a rapid deterioration of the lower frescoes (Solomidou-Ieronymidou, Hasapopoulos, 1993); to not make visible the manifestations of decay, part of the frescoes was covered with a cement plaster. Besides the descending humidity, increased by an inefficient disposal system and by the missing of a good waterproofing, manifests itself with various decays near to the roofs, above all in correspondence of the nave vault. In 1992, the Department of Antiquities of Cyprus carried out the restoration of the church, but unfortunately without resolving the humidity causes. So, the cycle of frescoes, partly restored and partly reintegrated with neutral tint finishing, show new degradation: detachments, efflorescence, exfoliation, color alteration, disintegration, coating biological and lacks. Similar manifestations are also evident in the basement. The area under the vault has an intermediate area with lacks and color changes.

The structural decay manifestations are concentrated on vaulted structures. The cross vault of women's gallery has an elevated keystone and cracks on intrados, that from keystone arrive almost to the end of the nails; at the extrados there is an abnormal inclination along the edge lines. There is a central depression corresponding to the larger nails and a lateral lowering corresponding to the smaller. The ogival barrel vault on the nave has a long cracking along the key section; the half-dome on the apse instead shows four lesions on the key that proceed radially to the middle band. Until now, all the lesions that emerged on the vaulted structures do not represent an immediate danger to the stability of the structure (except in the case of dynamic stresses or suddenly decays in the performance of the materials); however, it is necessary to proceed with specific investigations and a monitoring plan. Pre-diagnosis must be associated with the real diagnosis, through non-destructive investigations (ND) that can give answer to the hypotheses on the causes of the diseases. In this way the results of the investigations can be finally included in the pre-diagnostic abacus that was prepared in the HBIM model that can facilitate the monitoring of the deformation state.

\section{RESULTS}

Thanks to this project, there was the opportunity to work in an interdisciplinary team and to study the Saint John cathedral from multiple points of view. This generated heterogeneous information (historical, geometric, technical-constructive and state of decay) and led to the creation of a complex workflow in which several parallel activities were carried out, with the participation of several figures, each one specialized in a specific field: survey, restoration, archaeology, history of art and architecture. This collaboration has favoured the scientific framework for the design choices on the Saint John Cathedral. The interventions, essentially of a conservative nature, are aimed primarily at eliminating the degenerative causes, which despite recent restoration work, still compromise the cultural values of finishes and structures. The interventions have been simplified in categories: restoration from humidity, consolidation, cleaning, reintegration. To each category some identification charts have been associated, showing the codes, the description, the operative protocol and all the information useful for their complete definition. The sheets relating to the interventions have been integrated into the parametric model with two categories of elements: 'abacus of interventions' (created with the method of the hatching), and 'new parametric objects'. These latter have been defined in a new design phase in which the state of conservation and the intervention remain separate and distinguishable.

The convergence of the survey/modeling/mapping phase of degradation into a unique three-dimensional parametric and semantically enriched model, which can always be implemented with new information and/or new phases relating to maintenance and/or restoration projects, has allowed the subsequent export of all those documents (abaci, traditional drawings, etc.) useful for concluding and defining the entire cognitive phase and starting the design phase. In this way, instruments and methods tested, have responded to the needs of process flexibility within a project of complex restoration. 


\section{CONCLUSION}

In conclusion, this work pursues two main objectives:

- to preserve and learn about a valuable example of Cyprus's cultural and historical heritage, testimony to Orthodox art and architecture of the Ottoman period with valuable frescoes of the eighteenth century;

- to provide a starting point for future integrated projects, both in a Cypriot context, and to experiment the use of Information Modelling in the field of built heritage restoration.

The experimentation done on St. John's Cathedral has led to the creation of a unique, interconnected, interoperable, integrated and parametric 3D database that can be implemented. Among the problems encountered, the need to adapt and integrate parameters of the platform emerged: then a customized template was created to optimize the work of data organization.

The proposed template therefore provides for the insertion and modification of specific data, which can be divided into graphical-representative contents and informative contents.

Among the first ones, contents such as line thicknesses and imported annotation objects have been modified, whilst views ordered according to the traditional process of cognitive investigation have been created.

The informative contents, on the other hand, emerged during the information enrichment phase of the model; among these contents there are the TXT files of the classification of the technological system, the "filled regions" used for the mapping (degradation, pre-diagnosis and interventions), the shared parameters (LOD, Diachronic Analysis and all those of the detailed fields), as well as finally the personalized labels that show the references of the personalized parameters. The file thus created is among the other templates of the platform library and can be used for any new project that involves parametric modelling and management of a historical building.

According this approach, all data on the building have been merged into a single parametric, informative and multidisciplinary 3D model, allowing a holistic approach to the theme and without loss of information.

\section{REFERENCES}

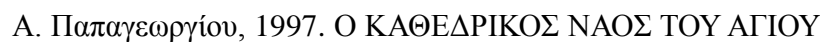

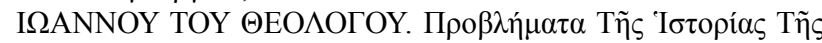

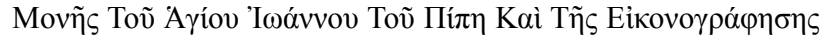

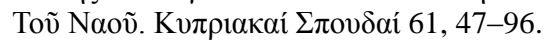

Brumana, R., Della Torre, S., Oreni, D., Previtali, M., Cantini, L., Barazzetti, L., Franchi, A., and Banfi, 2017. F.: HBIM Challenge Among The Paradigm Of Complexity, Tools And Preservation: The Basilica Di Collemaggio 8 Years After The Earthquake (L'Aquila). Int. Arch. Photogramm. Remote Sens. Spatial Inf. Sci., XLII-2/W5, pp 97-104

Bruno, N. and Roncella, R. (2018): A restoration oriented HBIM system for cultural heritage documentation: the case study of Parma cathedral, Int. Arch. Photogramm. Remote Sens. Spatial Inf. Sci., XLII-2, pp 171-178

Chiabrando, F., Lo Turco, M., and Rinaudo, 2017. F.: Modeling The Decay In An Hbim Starting From $3 d$ Point Clouds. A Followed Approach For Cultural Heritage Knowledge. Int. Arch. Photogramm. Remote Sens. Spatial Inf. Sci., XLII-2/W5, pp 605-612
Christou P., Elliotis M., 2016. Construction and Retrofit Methods of Stone Masonry Structures in Cyprus. The Open Construction and Building Technology Journal n.10, 249.

Dal Mas R. M., 2016. L'apporto Delle Nuove Tecnologie Di Rilievo Nel Restauro. Grimoldi, A., (ed) in RICerca/REStauro coordinamento Fiorani D., Sez. 2 A, Edizioni Quasar, Roma 2016.

Della Torre, S., Moioli , R., Pili, A. (2019) Digital tools supporting conservation and management of built cultural heritage. In, Edited ByKoenraad van Balen K,, Aziliz Vandesande A. (eds) Innovative built heritage models and preventive conservation. pp 101-106

Laurini C.R., 2018. H-BIM: metodologie integrate per il rilievo, l'analisi e il restauro della Saint John Cathedral di Nicosia. Degree thesis in Building Engineer and Architecture, DICAR - Dipartimento di Ingegneria Civile e Architettura and STARC - Science and technology in Archeology Research Center, University of Catania.

Pamart, A., Morlet, F., And De Luca, L.: A Fully Automated Incremental Photogrammetric Processing Dedicated For Collaborative Remote-Computing Workflow, Int. Arch. Photogramm. Remote Sens. Spatial Inf. Sci., XLII-2/W9, pp $565-571$

Papageorgiou, A., 2014. The Cathedral of Saint John the Evangelist. Nicosia: The Church Committee, 10.

Pavan A., Mirarchi C., Giani M., 2017. BIM: metodi e strumenti - Progettare, costruire e gestire nell'era digitale, Tecniche nuove Editore, Milano, 22.

Santana Quintero M., 2017. Harnessing Digital Workflows For Conserving Historic Places, Int. Arch. Photogramm. Remote Sens. Spatial Inf. Sci., XLII-5/W1, pp 9-14

Solomidou-Ieronymidou M., Hasapopoulos C., 1993. The vision of Saint John The Theologian - A unique 18th century wall painting in the cathedral of Nicosia. Report of the Department o Antiquities, Cyprus, 3.

\section{ACKNOWLEDGMENT}

The work was done within a multidisciplinary collaboration, but due to the specificity of the issues addressed: paragraphs $1,4.4$, 5 and 6 were edited by G. Sanfilippo; paragraphs 2, 4.6, 4.7 by C. Santagati; paragraph 3 by C. Santagati and Sorin Hermon; paragraph 4.1 by D. Papacharalambous and N. Bakirtzis, paragraphs $4.2,4.3,4.5$ by C. Laurini.

This work has been partially financed by the University of Catania within the project "Piano della Ricerca Dipartimentale 2016-2018" of the Department of Civil Engineering and Architecture. 